\title{
O reino deste Mundo: 0 Padroado e seus reflexos nas cartas de José de Anchieta
}

\section{Eduardo de Almeida Navarro}

Resumo Por meio da análise de algumas cartas de José de Anchieta, mostramos como a ação missionária jesuítica no século XVI não tinha quase nenhum espírito profético, estando submissa ao Estado, gerido por um rei-patrono. Palavraschave Padroado; jesuítas; catolicismo colonial; cartas.

Abstract Based on the analysis of some letters from Jose de Anchieta, we intend to show how Jesuitical mission work in the sixteenth century had almost no prophetical spirit, being submitted to a State run by a patron king. Keywords Royal sponsorship, jesuits; colonial Catholicism; letters. 
A atividade epistolográfica no Brasil colonial foi de grande importância, revelando o caráter da sociedade organizada em terras brasileiras nos primeiros séculos após o Descobrimento.

Buscaremos, aqui, analisar algumas cartas de José de Anchieta e nelas verificar a natureza e as características da práxis cristã dos jesuítas do século xvi no Brasil e seu comprometimento com uma determinada ordem político-institucional que, por meio do Padroado, condicionava a sua ação missionária.

\section{O poder político sublimado em poder religioso: o Padroado e a perda do caráter profético da Igreja em situação colonial no mundo ibérico}

Se a Igreja Católica é supranacional, por que os missionários católicos vindos para a América nos séculos XVI e XVII seriam majoritariamente portugueses e espanhóis? A resposta a tal indagação deve ser buscada numa instituição medieval que chegaria até a Idade Contemporânea: o Padroado. Instituído no século v, o Padroado era um expediente encontrado pelos papas para interessar os cristãos leigos na construção de templos e na manutenção de obras pias. Ao patrono incumbia despender recursos com tal fito, sendo-lhe concedidas honras e prebendas:

Patrono debetur honos, onus, emolumentum;

Praesentet, praesit, defendat, alatur egenus.'

Ao patrono deve-se honra, trabalho, vantagem;

Que proveja, comande, defenda, o necessitado seja alimentado.

A instituição do Padroado conduziria, entretanto, com o tempo, a graves desvios de suas finalidades precípuas, a verdadeiros abusos. Os patronos passavam a interferir em questões internas da Igreja, usufruíam de rendas dos mosteiros, das paróquias, cobravam tributos do clero etc. O Concílio de Trento (1545-1563) iria, assim, diminuir sua amplitude. Deixaria, porém, subsistir os padroados régios e os concedidos por "causa onerosa".

1 REGO, Silva. História das Missões do Padroado Português do Oriente. Lisboa: Agência Geral das Colônias, 1949, P. 94. 
Desse modo, aos reis de Portugal e da Espanha, os primeiros a colonizar regiões remotas da África, da Ásia e da América, seria concedido o Padroado e, assim, a eles incumbia o dever ou assistia o direito de evangelizar seus povos. Os reis da Espanha, Fernando e Isabel, foram designados pelo Papa Alexandre vi, em bula de 4 de maio de 1493, como Vicarii Christi para as terras americanas recémdescobertas. Eles e todos os seus sucessores declararam que a conversão dos indígenas constituía o alvo principal que perseguiam na América.

Com efeito, até o final da Idade Média sustentou-se a ideia de que os papas eram os senhores universais das terras possuídas pelos que não eram súditos da Igreja. Assim, por concessão pontifícia, D. Manuel I recebeu o título de "Senhor da Guiné" e de "Senhor da navegação, conquista e comércio da Etiópia, Arábia, Pérsia e Índia". Segundo João de Barros, a explicação de tal concessão deve-se procurar "nas muitas e grandes despezas que nestes reynos eram feitas".

- Padroado do Oriente e da América significava o poder de nomear bispos, de comandar a faina catequética e missionária. Nos primeiros versos d' Os Lusíadas, Camões afirma cantar também

\section{[...] a memória valerosa}

daqueles reis que foram dilatando

a fé e o império e as terras viciosas

de África e Ásia andaram devastando.

[Canto I, 2]

Assim, a empresa missionária, embora levada a efeito por uma instituição supranacional, que é a Igreja, assumia caráter nacional: no império espanhol atuariam missionários espanhóis ou de províncias religiosas espanholas (antes que se criassem, em ultramar, as províncias religiosas locais) e no império português atuariam missionários portugueses ou vinculados às províncias portuguesas das ordens religiosas. São célebres os casos de Francisco Xavier e do Pe. Tomás Estêvão, missionários jesuítas da Índia. O primeiro era espanhol e o segundo, inglês. Ambos, contudo, foram grandes fautores da difusão da língua portuguesa no 
Oriente. Francisco Xavier escreveu e fez que se escrevesse em português. Ele a si próprio denominou português e tratou El-Rey de Portugal como "nosso senhor" Já o Pe. Tomás Estêvão, autor de gramática da língua concani, aportuguesou seu próprio nome e baseou-se na pronúncia portuguesa para fazer transcrição naquele idioma. Segundo Cortez Pinto, "tão zeloso era o Pe. Estêvão do portuguesismo missionário que à hora da morte ainda acautelava os portugueses contra a admissão de estrangeiros no Estado da Índia". ${ }^{3}$

Assim, a obra missionária assumiu, desde o século xvi, um caráter nacional. Frágeis seriam, com efeito, os vínculos do clero com a hierarquia romana, vaticana. O Padroado teve o condão de resgatar o sentido missionário da Igreja. Até o século XVI as missões ocupavam, segundo Silva Rego, "um lugar manifestamente inferior na vida católica europeia. Não existia, sequer, o conceito de 'missão' no seu atual significado. Falava-se bastante na conversão de judeus e de sarracenos, mas o resto eram pagãos, paganos, palavra muito vaga ainda". ${ }^{4}$

Com os Descobrimentos, as fronteiras do mundo conhecido alargaram-se imensamente. A premente necessidade de evangelização das novas terras descobertas compeliu a Igreja a recorrer ao poder dos monarcas dos Estados nacionais emergentes com o fito de viabilizar tal projeto, que demandava largos recursos materiais (dentre os quais o controle de uma tecnologia náutica, sem a qual os missionários não poderiam atravessar os oceanos, ainda pouco singrados e repletos de perigos). Dessarte, de Igreja europeia ou cingida às plagas mediterrâneas, a Igreja converteu-se, de fato, com os Grandes Descobrimentos, em Igreja missionária, universal, "katholikê". Nunca o mandamento de Cristo "Ite et evangelizate omnes gentes" fora tão amplamente cumprido, de guisa que do Japão ao Brasil, da Índia ao Peru, os missionários católicos estariam presentes, desde o século xvi, na mudança da conformação cultural e religiosa do mundo.

Se a evangelização dos novos continentes era mister delegado aos reis patronos e se os primeiros que se lançaram à aventura do Atlântico, do Índico e do Pacífico foram os reis ibéricos, patente fica que o século xvi foi dominado pelas missões portuguesas e espanholas.

\footnotetext{
3 PINTO, A. C. Da famosa arte da imprimissão. Lisboa: Apostolado da Imprensa, 1948, p. 369.

4 REGO, Silva. Op. cit., p. 99
} 
Assim, em todo o mundo ibérico o ser católico implicava, de antemão, um comprometimento com os poderes deste mundo e, mais que isso, um comprometimento forçado, já que o Catolicismo era uma religião obrigatória.

\subsection{A colonização, a catolicidade e as ambiguidades dos reis-patronos}

A colonização foi um dos mais impressionantes e poderosos fatores de organização do espaço de que se tem notícia. Foi sob o regime de colonização que toda a superfície da terra foi submetida ao poder do Estado. Com efeito, até os Grandes Descobrimentos, grande parte do mundo ainda vivia sem ele: imensos territórios da América do Sul, da África e da Oceania eximiam-se de uma entidade que tivesse o "monopólio da força", para empregarmos a expressão de Weber. Com o advento da Idade Moderna, tal situação fatalmente se alteraria, iniciando-se um processo de completa dominação do espaço terrestre por estados nacionais. O capitalismo em sua fase mercantil deparava-se com espaços gigantescos, repletos de recursos naturais e que poderiam complementar as economias da Europa. A colonização europeizaria o mundo, conferindo à Europa a posição primacial de que gozou até a Segunda Guerra Mundial.

À expansão dos limites geográficos do mundo conhecido seguiu-se, com a colonização dos novos continentes nos séculos XVI e XVII, o mais impressionante movimento de alargamento da fé cristã na História. Além de ser religião salvacionista, o Cristianismo apresenta um elemento que, de per se, implica proselitismo. Com efeito, a crença num Deus que se faz homem, entrando na história da humanidade, subentende uma concepção universalista do ser humano, a ideia da sua unidade enquanto gênero. Assim, recusar o Evangelho, isto é, "a Boa Nova" a alguém equivale a excluí-lo da história da salvação, da qual só os seres brutos estão afastados. Segundo o missionário Antônio de Araújo, em seu Catecismo na língua brasílica, de 1618, dirigido aos índios tupis da costa,

So’o, pirá, gûyrá retãme’engaba é ikó 'ara; îandé rekoabamo nhote rimba'e pa’i Tupã îandébe i méengi biā... ${ }^{5}$

5 ARAÚJO, A. Catecismo na língua brasilica. Reprodução fac-similar da $1^{a}$ edição (1618), com apresentação do Pe. A. Lemos Barbosa. Rio de Janeiro: Pontifícia Universidade Católica do Rio de Janeiro, 1952. 
Este mundo é a terra prometida dos animais, dos peixes e dos pássaros; como nossa morada provisória, somente, o Senhor Deus a deu para nós. [Catecismo, 166v]

A ilação necessária dessa ideia é a da plena capacidade de todo homem de receber a doutrina cristã e a da premente necessidade da pregação da palavra revelada. Foi nesse sentido que o Papa Paulo III dirigiu a todo o orbe católico a bula Sublimis Deus, reconhecendo a plena capacidade dos índios de receber a doutrina cristã. Com efeito, não poderia haver uma humanidade paralela na América, na Ásia ou na África desconhecedora da primeira grande verdade do Cristianismo, a saber, a Encarnação do Verbo. Não admitir isso seria relativizar o texto bíblico, que aceita uma só criação por Deus. Seria como aceitar que o Cristianismo é uma religião com determinismos históricos e não detentora de uma verdade universal. A ideia da existência de diferentes "humanidades" preconizada pelo estruturalismo de Claude Lévi-Strauss, a descontinuidade temporal da razão e a recusa da História, pontos nevrálgicos de uma reflexão que empolgaria muitos espíritos no século $\mathrm{xx}$, são fortes ameaças ao Cristianismo, por natureza universalista.

Mas se o rei-patrono foi incumbido pelo Papa de evangelizar os novos continentes descobertos, ele também é o chefe de um estado mercantil, onde uma nova classe social, a burguesia, com seus lucros estupendos fortalecia a economia do Estado por ele gerido. Mas como conciliar o alto cometimento que a Igreja lhe fazia com a necessidade de fortalecer a atividade econômica? A figura dos reis ibéricos sob o Padroado estará permanentemente impregnada de paradoxos, de ambiguidades que só seriam superadas séculos mais tarde. As determinações régias que proibiam a escravidão indígena seriam sistematicamente transgredidas ou ressignificadas de acordo com os interesses das elites econômicas locais. Afinal, as realidades materiais eram tão concretas e o reino estava tão distante...

\section{As manifestações do poder do rei-patrono no epistolário anchietano}

Interessa-nos, aqui, como já assinalamos anteriormente, analisar o conteúdo de algumas cartas de José de Anchieta, escritas desde o ano de 1553, para podermos aquilatar características da prática pastoral e do pensamento dos primeiros jesuítas do Brasil, a refletir o regime do Padroado. 
Anchieta, em seu epistolário, revela que a prática cristã desses primeiros jesuítas se enreda em contradições insuperáveis. Evidenciam-se ali diferentes esferas de interesses: a do colonizador, propriamente dito, com a presunção escancarada de que colonizar o Brasil implicava eliminar restrições de natureza religiosa ou ética para escravizar os índios; a do missionário, a praticar uma pastoral eminentemente sacramental, que queria impedir a escravização dos índios para colocá-los sob sua esfera de poder em aldeamentos imensos que possuíam uma economia pujante e onde a práxis cristã dos recém-convertidos seria controlada; a esfera dos índios não convertidos, a quem se apresentavam as opções de submeter-se, fugir, lutar ou morrer; e, finalmente, a esfera do poder real, ainda impregnado da ideologia da Guerra Santa mas já pressionado pelos reclamos de uma classe social mercantil (revolucionária nos séculos XVI, XVII e XVIII), para quem a ação missionária era, muitas vezes, um empecilho a seu total desenvolvimento.

Entre os fatos retratados na epistolografia anchietana e que apresentam relação com o regime do Padroado, os mais evidentes são:

\section{1. A catequese dos índios a serviço da manutenção do império colonial português}

Em carta escrita a El-Rey nos anos em que era provincial da Companhia de Jesus no Brasil, Anchieta mostra como desapareciam os índios da costa brasileira. Nessa carta a figura do rei sobreleva-se como a de um poder em prol da realização do bem e da justiça. Em nenhum momento os missionários quinhentistas do mundo colonial ibérico poriam em dúvida a ideia de que os "cristianíssimos reis" tinham como objetivo primeiro o "acrescentamento da santa fé católica". Em Anchieta também tal visão nunca é problematizada:

Porque a maior parte dos índios naturais do Brasil está consumida e alguns poucos que se hão conservado com a diligência e trabalhos da Companhia são tão oprimidos que em pouco tempo se gastarão. Pelo que têm muita necessidade de particular favor de Vossa Majestade. ${ }^{6}$

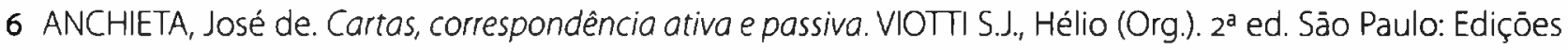
Loyola, 1984, p. 338. 
Que os negócios e os interesses do Estado estivessem de envolta com os pios misteres de um missionário dá-nos conta a carta dirigida a Inácio de Loyola, escrita de Piratininga em julho de 1554:

Estando nosso padre na Bahia de Todos os Santos, determinou Sua Alteza mandar doze homens pelo sertão a descobrir ouro, que diziam existir, para o que o Governador Tomé de Souza pediu um padre, que fosse com eles em lugar de Cristo a fim de não irem desamparados. [...] Mandou com eles o Pe. Navarro. Eles vão buscar ouro e ele vai buscar tesouro de almas, que naqueles lugares há muito copioso.?

O capitalismo mercantil precisava ainda das bênçãos da Igreja para sacramentar sua prática espoliadora e acumulativa. No século XvI ainda não havia nenhuma formulação teórica que tivesse o condão de revolucionar tal modelo de sociedade. Não se podem considerar inexistentes nessa época os espíritos carismáticos que, no seio de uma estrutura burocratizada, rejuvenescessem a ordem opressora e sem nenhum espírito profético, como foi o caso do grande Bartolomeu de las Casas. Mas suas denúncias contra essa Igreja que sacramentava o lucro e o mercantilismo não tiveram sempre consequências significativas na remodelação de suas estruturas.

\subsection{O braço armado da fé: a política de aldeamentos}

Um outro aspecto da submissão da ação jesuítica quinhentista ao regime do Padroado foi a instituição dos aldeamentos. Um aldeamento não é o mesmo que uma aldeia indígena. Esta é um fato social natural, o lugar em que viviam os índios de uma determinada etnia e de uma mesma língua. Já um aldeamento é um fato social artificial, congregando índios de diferentes etnias e, muitas vezes, de diferentes línguas e culturas, trazidos que eram de diversos lugares. $O$ aldeamento veio em resposta à extrema dificuldade que os primeiros missionários encontravam em catequizar os índios em suas aldeias, devido à sua aludida "inconstância" e à sua resistência em se livrar de certas práticas culturais consideradas condenáveis, como

7 ANCHIETA, José de. Minhas cartas. São Paulo: Casa de Anchieta/Associaçāo Comercial de Sāo Paulo, 2004, p. 14. 
a antropofagia e a poligamia. Com efeito, são frequentes nas cartas de Anchieta as expressões de desalento diante dos fracassos da catequese dos adultos:

[...] Como era possivel que pudéssemos sofrer tanto tempo e com tanta alegria tamanha dureza de coração dos brasis que ensinamos, ouvidos tão cerrados à palavra divina, tão fácil renúncia aos bons costumes, se é que alguns hão aprendido, recaída tão rápida nos costumes e pecados de seus antepassados e, finalmente, tão pouco ou nenhum cuidado de sua própria salvação, se as contínuas orações da Companhia não nos dessem mui grande ajuda? ${ }^{8}$

Nessa mesma carta dirigida ao geral Pe. Diogo Laínes, datada de $1^{\circ}$ de junho de 1560, Anchieta afirmou seu desejo de ver o braço armado do Estado facilitar seu trabalho apostólico:

Assim, não existe dúvida senão que neles se faria muito fruto se estivessem juntos, onde se pudessem doutrinar, de que se tem experiência agora na Bahia, onde, juntados em umas grandes aldeias, por ordem do governador, aprendem da melhor vontade a doutrina e rudimentos da fé e dão muito fruto, que durará enquanto houver quem os faça viver naquela sujeição e temor. ${ }^{9}$

Foi principalmente um fato político o que determinou a criação dos aldeamentos. Eles eram uma reserva de força militar usada amiúde e sempre que a segurança da colônia estivesse ameaçada. A própria manutenção do Brasil sob o império português ficaria impossibilitada sem o elemento indígena, imprescindível para a luta contra os invasores: "Porque bem se deixa ver, e os portugueses assim o confessam, que sem eles mal se poderá conservar este Estado do Brasil".`^

Os aldeamentos, por outro lado, eram um poderoso fator de destruição cultural por reunirem índios de diferentes etnias e línguas, assim como pelas seguintes razões: 1) Sua conformação espacial subvertia os padrões indígenas tradicionais

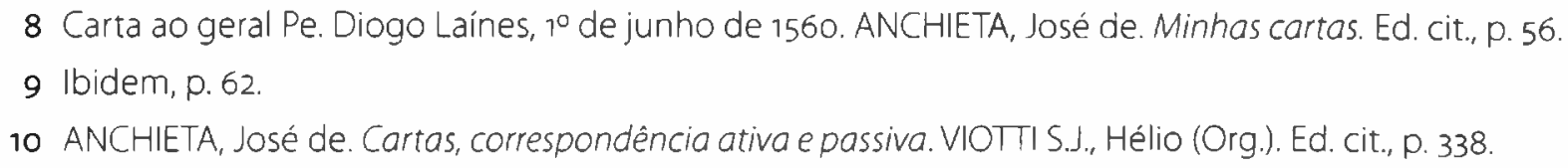


de organização de aldeias. Saindo de habitações onde viviam mais de cem pessoas, com famílias extensas, os índios passavam a viver em casas pequenas, edificadas segundo padrões europeus, para famílias nucleares compostas de pai, mãe e filhos. Além disso, a dispersão geográfica dos índios, desconhecedores do poder político e do Estado, dava lugar à concentração espacial de milhares de pessoas sob a tutela dos padres, a quem deveriam obedecer e submeter-se. 2) Eram subvertidos os padrões de divisão sexual do trabalho existentes nas aldeias indígenas, onde plantar roças cabia às mulheres e não aos homens. Para um homem tupi o plantar roça correspondia a emascular-se.

\subsection{Uma pastoral eminentemente sacramental e sem espírito profético}

Sedimentou-se ao longo dos séculos uma representação de Anchieta como "taumaturgo", "apóstolo do Brasil" e "educador dos índios". Uma análise de suas cartas mostra-nos, com efeito, que sua ação pastoral quase que se resumia à administração dos sacramentos. Era esse o cerne do trabalho apostólico jesuítico no século XVI. Salvar as almas, batizando-as, crismando-as, casar os índios segundo os ritos da Igreja, tornar os homens dóceis ao trabalho, libertos da poligamia e do amancebamento, enfim, criar uma nova alma indígena; esse seria o alvo daqueles missionários, entre os quais Anchieta:

O ministério do ano inteiro com os índios consiste no seguinte: ensinar-lhes e explicarlhes a doutrina cristã, batizá-los, uni-los pelo matrimônio, visitar os enfermos, ungir os doentes com os santos óleos, sepultar os mortos, dedicar-se à salvação de quantos lhes estão confiados, manter escolas primárias, em que os meninos aprendem também, com muita diligência, a arte do canto e a tocar flautas e charamelas. Dão muito relevo, com o canto de órgão, às vésperas e missas, quer nas aldeias, quer no nosso colégio, nos dias consagrados às santas relíquias."

No que tange à pastoral educacional dos jesuítas do Quinhentos, vemos acima que, para os meninos índios, garantia-se somente a escola primária. Já para os

11 Carta ânua da província do Brasil, de 1583, datada de $1^{\circ}$ de janeiro de 1584. ANCHIETA, José de. Minhas cartas. Ed. cit, p. 116. 
filhos dos portugueses havia a escola humanística: "Os meninos da escola primária, que completam o número de oitenta, dão mostra incomum de sua virtude. Com muita aplicação, procuram traçar as primeiras letras, para se poderem transferir depois às aulas de latim".12

$\mathrm{Na}$ verdade, a prática educativa junto aos índios era um desdobramento do trabalho catequético, a garantia de sua consolidação e de seus resultados, considerados ruins por muitos. Para obviar a tais problemas é que se alfabetizavam os meninos índios. Diz Anchieta em sua carta trimestral de maio a agosto de 1556 que

[...] quase todos vêm duas vezes por dia à escola, sobretudo de manhã. [...] Mas o principal cuidado que temos deles está em lhes declararmos os rudimentos da fé, sem descuidar o ensino das letras; estimam-no tanto que, se não fosse esta atração, talvez nem os pudéssemos levar a mais nada. ${ }^{13}$

Com efeito, um índio alfabetizado passaria a assumir um novo ethos, diferente do de seus pais, isto é, seria conduzido ao corpo místico de Cristo, tornando-se, consequentemente, um súdito do rei-patrono de Portugal. Mas ele não receberia os tesouros da cultura humanística, destinada aos filhos dos colonos abastados.

A pastoral dos escravos também era exclusivamente sacramental. Escrevendo em $1^{\circ}$ de janeiro de 1584 , de Salvador, na condição de provincial do Brasil, ao geral Pe. Cláudio Acquaviva, Anchieta diria: "Além das pregações sobreditas, todos os dias é ministrado o catecismo pelos nossos aos índios e africanos (de que há muitíssimos nesta cidade). Ouvem-lhes as confissões e aos pagãos preparam-nos para o batismo."14 Segundo Anchieta, havia escravas virtuosas que resistiam ao assédio sexual de seus senhores. Mas, apesar de as saber maltratadas, Anchieta jamais questionou a instituição da escravidão, haja vista que esta se inscrevia na ordem jurídica vigente, diante da qual Anchieta jamais manifestaria desassossego, diferentemente de Antônio Vieira, que, em vários de seus textos, revela sua percepção do hiato entre a ação missionária e os ensinamentos de Jesus. Segundo Alfredo Bosi, "como

\footnotetext{
12 Ibidem, p. 117.

13 Carta trimestral de maio a agosto de 1556. Ibidem., p. 23.

14 Carta ânua da provincia do Brasil, de 1583. Ibidem, p. 114.
} 
poderia uma instituição que vivia dentro do Estado monárquico e à custa dos excedentes deste, desenvolver projeto social coeso à revelia das forças que dominavam esse mesmo sistema?" 15 Era o primado do formalismo, era uma Igreja que, voltada à salvação das almas, não apresentava questionamento algum da iniquidade que fazia os tormentos dos corpos dos pobres: "Observam-se em muitos, máxime nas mulheres, assim livres como escravas, mui manifestos sinais de virtude, principalmente em fugir e detestar a luxúria [...]. Sofrem as escravas que seus senhores as maltratem com bofetadas, murros e açoites por não consentir no pecado"."

\section{Conclusōes Segundo Leonardo Boff,}

a América Latina foi missionada dentro de um determinado modelo de Igreja, aquele próprio do Padroado. Segundo este modelo, a Igreja se faz presente no mundo mediante um pacto com o Estado, que provê todas as suas necessidades e garante seu funcionamento. [...] No nível doutrinário, este tipo de Igreja se mostra conservador e ortodoxo. [...] Por outro lado, há uma tendência, hoje, em se afirmar [...] numa visão mais estritamente histórica, que a Igreja não estava nas cogitações do Jesus histórico."

É com esse olhar que o homem contemporâneo secularizado geralmente interpreta as sociedades estamentais do mundo colonial. Seguramente não é esse o modo mais isento da possibilidade de erros. Mas, ainda que a inserção num contexto de época possa absolver Anchieta e seus coetâneos jesuítas (e julgar homens fora de suas épocas é atitude temerária), é verdade também que o século XVI produziu espíritos autenticamente proféticos, como Bartolomeu de las Casas, perseguido pelos poderes constituídos de sua época.

Instaurou-se nos séculos dos Grandes Descobrimentos uma contradição insuperável: como pregar a Boa Nova e manter a pureza de uma doutrina que revolucionou

\footnotetext{
15 BOSI, Alfredo. Dialética da colonização. Sāo Paulo: Companhia das Letras, 2005, p. 137.

16 Carta de São Vicente ao geral Pe. Diogo Laínes, de $1^{\circ}$ de junho de 1560. ANCHIETA, José de. Minhas cartas. Ed. cit., p. 63.

17 BOFF, Leonardo. Igreja, carisma e poder. Sāo Paulo: Ática, 1994.
} 
o mundo antigo dentro de uma ordem política que burocratizaria o carisma de seu fundador, o mestre de Nazaré? Como as ideias de Jesus poderiam redundar, num estado gerido por um rei-patrono, senão na mais acomodatícia doutrina, toda cheia de compromissos temporais e seculares, ainda que propagada por zelosos missionários que fizeram a própria oblação de suas vidas para levá-la a outros povos? Nem sempre o dar a vida por uma causa implica a grandeza desta. A História mostra-nos que grandes tiranos e genocidas do século xx também deram a vida por suas causas. $\mathrm{E}$ as boas intenções nem sempre levam inequivocamente ao bem...

Eduardo de Almeida Navarro é livre-docente do Departamento de Letras Clássicas e Vernáculas da Universidade de São Paulo, onde leciona Tupi Antigo e Literatura Colonial Brasileira. É autor de Método moderno de tupi antigo - a língua do Brasil dos primeiros séculos [Global] e de Teatro de Anchieta [Martins Fontes], entre outros trabalhos. 